\title{
Effect of the Steam Activation Thermal Treatment on the Microstructure of Continuous $\mathrm{TiO}_{2}$ Fibers
}

\author{
Xiangchao Zhang, ${ }^{1}$ Shiying Zhang, ${ }^{1,2}$ Yang You, ${ }^{1}$ and Yunlong $\mathrm{Li}^{1}$ \\ ${ }^{1}$ Department of Biological and Environmental Science, Institute of New Materials, Changsha University, Changsha 410022, China \\ ${ }^{2}$ State Key Laboratory Breeding Base of Photocatalysis, Fuzhou University, Fuzhou 350002, China
}

Correspondence should be addressed to Shiying Zhang, cdzhangshiying@163.com

Received 17 April 2012; Accepted 6 June 2012

Academic Editor: Jiaguo Yu

Copyright (C) 2012 Xiangchao Zhang et al. This is an open access article distributed under the Creative Commons Attribution License, which permits unrestricted use, distribution, and reproduction in any medium, provided the original work is properly cited.

The continuous $\mathrm{TiO}_{2}$ fibers have been synthesized by the sol-gel method using the polymer of titanate as the precursor solution. The as-synthesized samples were characterized using XRD, SEM, and HR-TEM analysis methods. The grain growth kinetics was primarily investigated. The results demonstrated that the average diameters of the fibers were in the range of $20-30 \mu \mathrm{m}$, the crystal phase of the synthesized $\mathrm{TiO}_{2}$ fiber was transformed from anasate to rutile, and the crystal size became bigger with increasing the temperature using steam activation. The growth exponent and the constant of growth rate of the rutile crystal phase at $500^{\circ} \mathrm{C}$ were 4 and $2.55 \times 10^{6} \mathrm{~nm} / \mathrm{h}$, respectively. The activation energies of crystalline growth during $500^{\circ} \mathrm{C} \sim 700^{\circ} \mathrm{C}$ and $700^{\circ} \mathrm{C} \sim 800^{\circ} \mathrm{C}$ were $38.62 \mathrm{~kJ} / \mathrm{mol}$ and $143.91 \mathrm{~kJ} / \mathrm{mol}$, respectively.

\section{Introduction}

Since Fujishima and Honda discovered the photocatalytic splitting of water on a $\mathrm{TiO}_{2}$ electrode under ultraviolet light [1], enormous efforts have been devoted to the research of $\mathrm{TiO}_{2}$ material due to its excellent optical, electrical, photocatalytic, and thermal properties, which has led to many promising applications in areas ranging from photovoltaics and photocatalysis to sensors and potential tool in cancer treatment $[2,3]$. It is well known that $\mathrm{TiO}_{2}$ nanomaterials are playing and will continue to play an important role in the protections of the environment and in the search for renewable and clean energy technologies $[4,5]$. Controlling the morphological properties of materials during synthesis is of great importance, as these structural characteristics strongly influence their performances and purposes. In order to maximize its performance, much effort has been dedicated to designing and controlling the morphology of $\mathrm{TiO}_{2}$ from the macroscopic to the nanometer scale [6-8], such as nanorods, nanoflowers, nanotubes, nanofibers, and hollow spheres. However, it is still facing challenge during the application of these materials in wastewater disposal due to difficult separation from solution because of their microsize
[9]. Due to the very large aspect ratios (length to diameter) of fiber, photocatalyst in the form of fiber is superior to particles as far as the recycling and aggregation are concerned. On the other hand, it is generally accepted that the properties of $\mathrm{TiO}_{2}$ fibers depend on their microstructure, morphology, porosity, and crystallinity. Preparation methods enabling the control of the structural properties are especially desired $[10,11]$. Since 1934, Formhals patented the first invention of electrostatic spinning of fibers [12]. Several preparation methods of $\mathrm{TiO}_{2}$ fibers have been reported [13-15], such as the KDC (kneading-drying-calcination) method, sol-gel process, hydrothermal method, and electrospinning.

As we known, the thermal treatment process would play a critical role in controlling the physicochemical properties of ceramic materials and catalysts using sol-gel methods. In our previous work [16], we have reported that the $100^{\circ} \mathrm{C}$, $500^{\circ} \mathrm{C}$, freeze drying, and microwave heating pretreatment process have obviously affected morphology, crystallinity, and optical properties of sol-gel-derived $\mathrm{TiO}_{2}$ film due to the different heating mechanism. The steam activation has been used as an effective thermal treatment process to synthesize the activated carbon fibers (ACFs) [17, 18]. However, to our knowledge, there is no report on the effect of the steam 
activation thermal treatment process on the microstructure of continuous $\mathrm{TiO}_{2}$ fibers.

In this work, the continuous $\mathrm{TiO}_{2}$ fibers have been synthesized by the sol-gel method using the polymer of titanate as the precursor solutions. The effects of the time and the temperature during steam activation thermal treatment process on the microstructure of the as-synthesized samples were characterized using X-ray diffraction (XRD), scanning electron microscope (SEM), and high-resolution transmission electron microscopy (HR-TEM) analysis methods. The nanocrystalline growth kinetics mechanism inside continuous $\mathrm{TiO}_{2}$ fibers was primarily investigated.

\section{Experimental}

2.1. Preparation of Continuous $\mathrm{TiO}_{2}$ Fibers. The continuous $\mathrm{TiO}_{2}$ fibers were synthesized by sol-gel method, using titanium tetrabutoxide $\left(\mathrm{Ti}\left(\mathrm{OC}_{4} \mathrm{H}_{9}\right)_{4}\right.$, TTBO), anhydrous alcohol $\left(\mathrm{C}_{2} \mathrm{H}_{5} \mathrm{OH}, \mathrm{EtOH}\right)$, polyvinylpyrrolidone $\left(\left(\mathrm{C}_{6} \mathrm{H}_{9} \mathrm{NO}\right)_{n}\right.$, molecular weight 1000, PVP), and hydrochloric acid ( $\mathrm{HCl}$, $6 \mathrm{~mol} / \mathrm{L}, \mathrm{HCl}$ ) as starting materials. All reagents were analytical grade and used without further purification. In typical synthesis process, $105.10 \mathrm{~mL}$ TTBO was mixed with $25.66 \mathrm{~mL} \mathrm{EtOH}$ and magneticly-stirred for $60 \mathrm{~min}$ at room temperature and nominated as "solution A." Solution B was prepared by mixing $10.00 \mathrm{~g}(0.01 \mathrm{~mol}) \mathrm{PVP}$ and $5.60 \mathrm{~g} \mathrm{HCl}$ $(6 \mathrm{~mol} / \mathrm{L})$ dissolving in $76.98 \mathrm{~mL} \mathrm{EtOH}$. Solution B was added to solution A drop by drop keeping vigorous stirring for $120 \mathrm{~min}$; during the stage of stirring process, the TTBO was hydrolyzed with the $\mathrm{H}_{2} \mathrm{O}$ in the $\mathrm{HCl}(6 \mathrm{~mol} / \mathrm{L})$. On the other hand, $\mathrm{HCl}$ serves as a stabilizer to hinder the hydrolysis of TTBO. The improvement of viscosity of precursor colossal of polymer titanate is achieved by adding PVP. The chemical composition of the starting alkoxide solution was PVP:TTBO: EtOH $: \mathrm{H}_{2} \mathrm{O}=0.04: 1: 8: 1: 1$ in molar ratio. The sol was evaporated by a rotary evaporator in oil bath at $110-150^{\circ} \mathrm{C}$ to prepare the spinnable solution, corresponding to the viscosity of $5 \mathrm{~Pa} \cdot \mathrm{s}$. Then, the long continuous precursor fibers were obtained by homemade spinning apparatus. After calcined at $300-800^{\circ} \mathrm{C}$ with steam activation, the continuous $\mathrm{TiO}_{2}$ fibers have been prepared.

2.2. Characterization. Crystal structures of the synthesized $\mathrm{TiO}_{2}$ fibers were identified by X-ray diffraction (XRD) using a Rigaku $D / \max 2550$ diffractometer with graphite monochromatized $\mathrm{Cu} K_{\alpha}$ radiation $(\lambda=1.54056 \AA)$. The different patterns were collected at a step of $0.02^{\circ}$ in the $2 \theta$ range from $10^{\circ}$ to $80^{\circ}$. The accelerating voltage and the applied current were $50 \mathrm{kV}$ and $100 \mathrm{~mA}$, respectively. Phases were measured using the Search/Match capabilities of the JADE 5.0 program along with the ICDD (International Center for Diffraction Data) powder diffraction file (PDF) database. $\mathrm{TiO}_{2}$ fiber morphology was characterized by scanning electron microscopy (SEM, JSM-6700F) at an operating accelerating voltage of $20 \mathrm{kV}$ and high-resolution transmission electron microscopy (HR-TEM, JEM-3010) at accelerating voltage of $200 \mathrm{kV}$, respectively. In a typical SEM measurement, the samples were mounted on a 200 mesh carbon-coated copper grid and sputtered with a gold-palladium alloy to prevent electrical charging during the SEM analysis. The specimens for TEM imaging were prepared by suspending solid samples (the fibers were milled by agate mortar) in absolute ethanol and immediately evaporated at ambient temperature.

\section{Results and Discussion}

The XRD patterns of the heat-treated continuous $\mathrm{TiO}_{2}$ fibers at $300-800^{\circ} \mathrm{C}$ using steam activation for $90 \mathrm{~min}$ are shown in Figure 1, which revealed the presence of anatase and/or rutile phases of $\mathrm{TiO}_{2}$ depending on the calcination temperatures. The presence of peaks can be readily indexed to diffraction peak of anatase phase $\mathrm{TiO}_{2}$ (JCPDS 21-1272) and rutile phases of $\mathrm{TiO}_{2}$ (JCPDS 21-1276), respectively. At 300 and $400^{\circ} \mathrm{C}$, all the peaks can be assigned to anatase $\mathrm{TiO}_{2}$ and the peaks appear broad indicating that the crystalline is not very well. Besides the peak of anatase $\mathrm{TiO}_{2}$, the new peaks associated with rutile phases of $\mathrm{TiO}_{2}$ were observed in the pattern of the sample after calcination at $500^{\circ} \mathrm{C}$. The results indicated that the phase transformation from anatase to rutile appeared at $500^{\circ} \mathrm{C}$. With the increase of temperature from $600^{\circ} \mathrm{C}$ to $800^{\circ} \mathrm{C}$, the anatase to rutile phase transformation had already completed. The crystallite size $(D)$ of anatase and rutile $\mathrm{TiO}_{2}$ inside the continuous fibers were estimated using the Scherrer formula:

$$
D=\frac{0.89 \lambda}{B \cos \theta}
$$

where $B$ is the half-width of the diffraction peak, $\theta$ is the diffraction angle, and $\lambda$ is the $\mathrm{X}$-ray wavelength. Figure 2 shows a plot of the crystal size of anatase and rutile $\mathrm{TiO}_{2}$ as a function of calcination temperature. The crystal size of anatase $\mathrm{TiO}_{2}$ increased slowly from about $12.2 \mathrm{~nm}$ at $300^{\circ} \mathrm{C}$ to $36.9 \mathrm{~nm}$ at $500^{\circ} \mathrm{C}$, while the crystal size of rutile $\mathrm{TiO}_{2}$ rapidly increased from $58.6 \mathrm{~nm}$ to $122.8 \mathrm{~nm}$ with increasing the calcination temperature from $500^{\circ} \mathrm{C}$ to $800^{\circ} \mathrm{C}$. The results indicated that the crystal size became bigger with increasing the thermal treatment temperature using steam activation.

Figure 3 shows the XRD patterns of the continuous $\mathrm{TiO}_{2}$ fibers calcined $500^{\circ} \mathrm{C}$ at different thermal treatment times using steam activation. It can be seen that the synthesized continuous $\mathrm{TiO}_{2}$ fibers appear at the anatase and rutile phases. The peaks of anatase phases became gradually weaken and that of rutile phases were enhanced evidently with increasing the steam activation times. The results indicated that it was beneficial for the continuous $\mathrm{TiO}_{2}$ fibers to produce phase transformation from anatase to rutile with increasing the steam activation time. By using the Scherrer's formula, effect of the different thermal treatment times on the average crystal sizes of $\mathrm{TiO}_{2}$ calcined $500^{\circ} \mathrm{C}$ are shown in Figure 4. The crystal size of anatase crystalline phase increased from $18.5 \mathrm{~nm}$ to $37.4 \mathrm{~nm}$, and the crystal size of rutile crystalline phase increased from $44.6 \mathrm{~nm}$ to $58.6 \mathrm{~nm}$. The crystalline size of anatase phase first increased rapidly, and then kept constant, whereas that of rutile phase gradually 


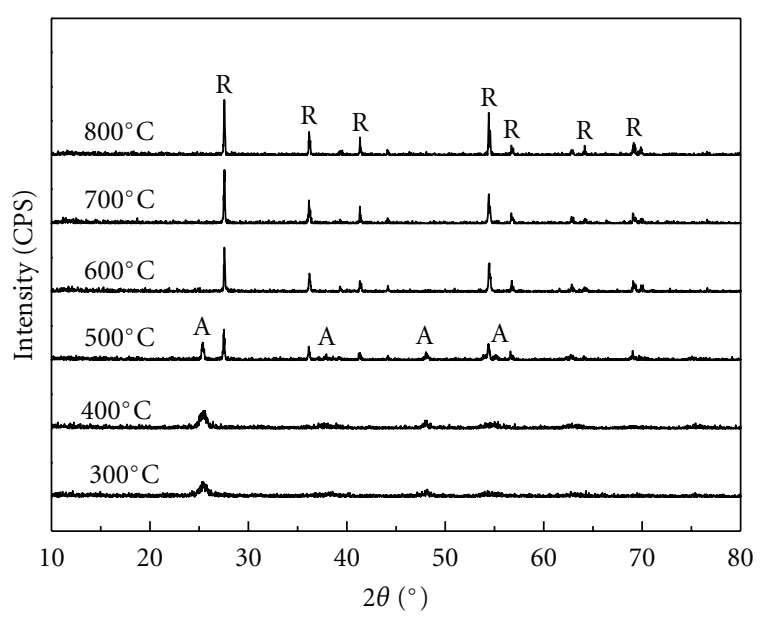

A: Anatase

R: Rutile

FIGURE 1: XRD patterns for the continuous $\mathrm{TiO}_{2}$ fibers at different thermal treatment temperatures using steam activation.

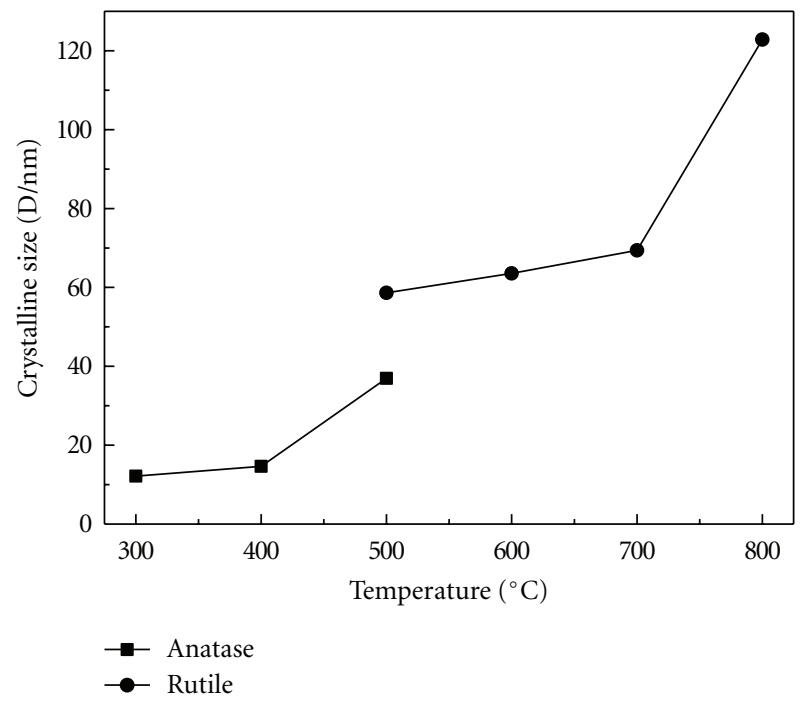

FIGURE 2: Effect of the different thermal treatment temperatures using steam activation on the average crystal sizes inside the continuous $\mathrm{TiO}_{2}$ fibers.

increased with increasing the steam activation time. The mass fraction of anatase phase $\left(W_{A}\right)$ at one temperature can be calculated from the following formula [19]:

$$
W_{A} \%=\frac{100}{\left(1+1.265 I_{R} / I_{A}\right)} \text {. }
$$

Here $W_{A}$ is the mass fraction of anatase, and $I_{A}$ and $I_{R}$ represent the integrated intensities of the anatase $(101)$ and rutile (110), respectively. The $W_{A}$ values were $73.3 \%, 32.2 \%$, $31.3 \%, 16.8 \%$, and $11.9 \%$ for $500^{\circ} \mathrm{C}$ calcination using steam activation $30 \mathrm{~min}, 60 \mathrm{~min}, 90 \mathrm{~min}, 120 \mathrm{~min}$, and $150 \mathrm{~min}$, respectively. The mass percentage of anatase phase decreased gradually with increasing the time of steam activation.

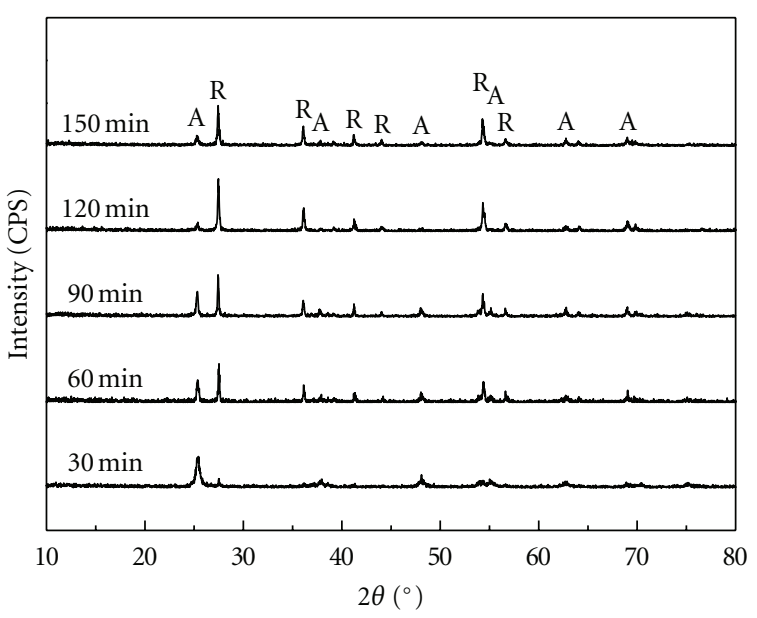

A: Anatase

R: Rutile

FIgure 3: XRD patterns for the continuous $\mathrm{TiO}_{2}$ fibers calcined $500^{\circ} \mathrm{C}$ at different thermal treatment times using steam activation.

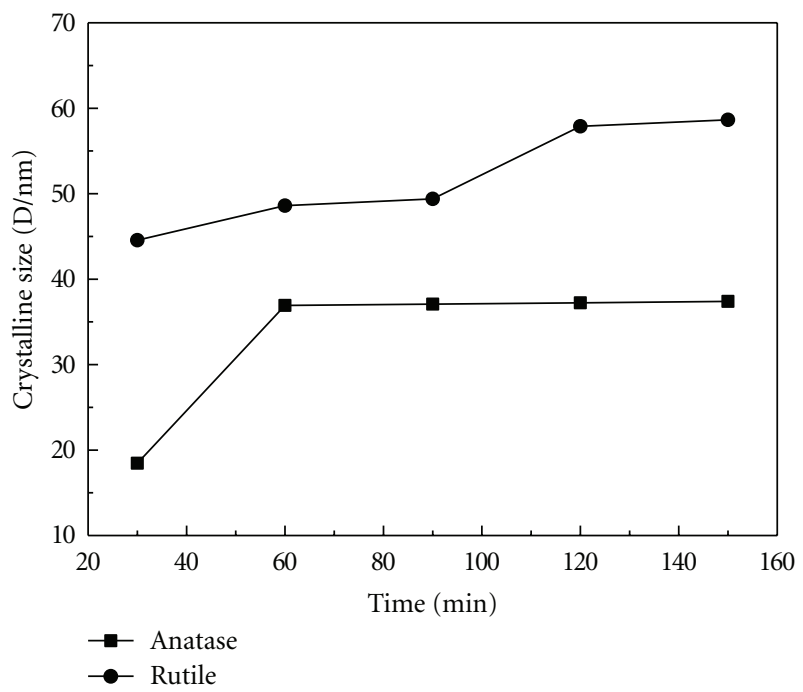

Figure 4: Effect of the different thermal treatment times using steam activation on the average crystal sizes inside the continuous $\mathrm{TiO}_{2}$ fibers calcined $500^{\circ} \mathrm{C}$.

Figure 5 shows TEM and HRTEM images of the continuous $\mathrm{TiO}_{2}$ fibers calcined $300^{\circ} \mathrm{C}, 500^{\circ} \mathrm{C}$, and $700^{\circ} \mathrm{C}$ using steam activation for $90 \mathrm{~min}$. At $300^{\circ} \mathrm{C}$ calcination using steam activation, the particle size of $\mathrm{TiO}_{2}$ with uniform distribution was about $15 \mathrm{~nm}$ in diameter (Figure 5(a)). Also, we know that the lattice images are interference patterns between the direct beam and diffracted beams in HR-TEM, and the spacing of a set of fringes is proportional to the lattice spacing, when the corresponding lattice planes meet the Bragg condition. It showed faintly lattice fringes, which was in good agreement with the peaks appearing broad from $\mathrm{XRD}$ analysis. It could be seen that the crystalline size of the $500^{\circ} \mathrm{C}$ calcination became obviously increasing compared with that of $300^{\circ} \mathrm{C}$ calcination from Figures 5(c) and 5(d). 


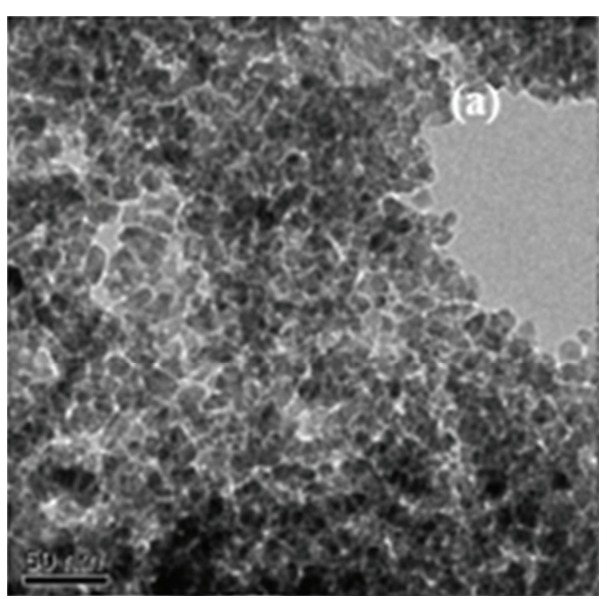

(a)

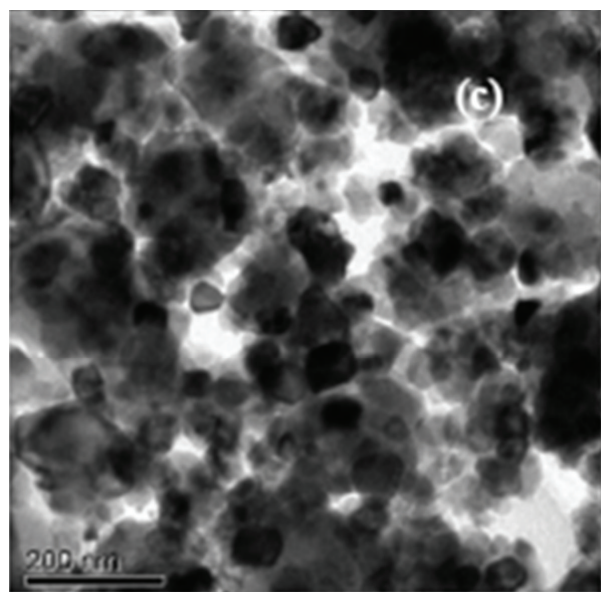

(c)

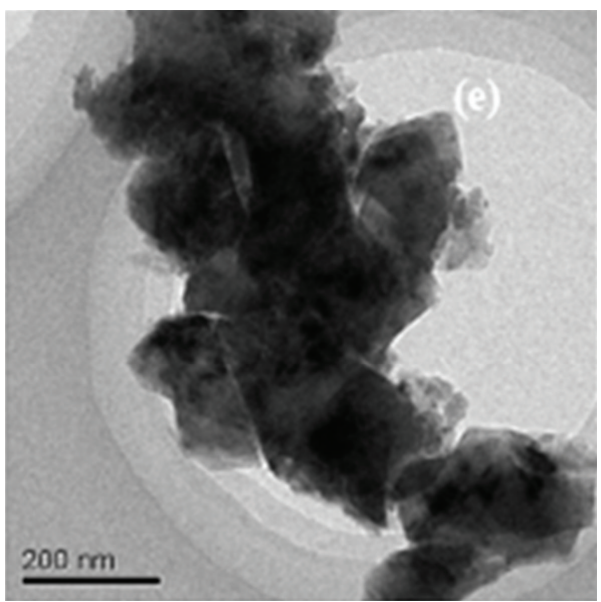

(e)

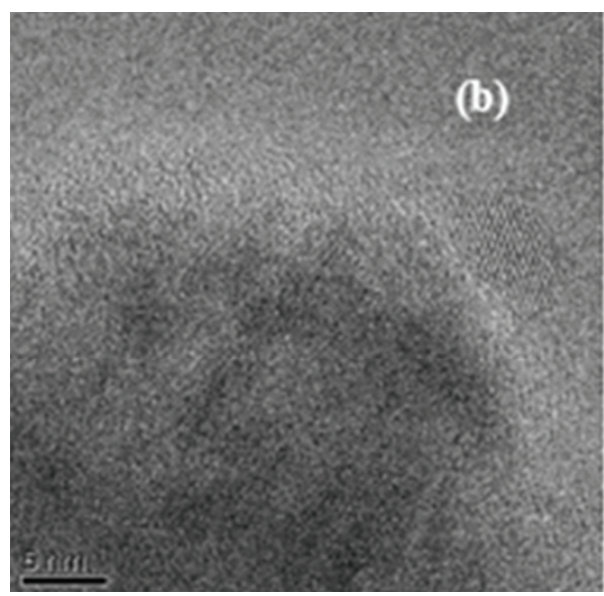

(b)

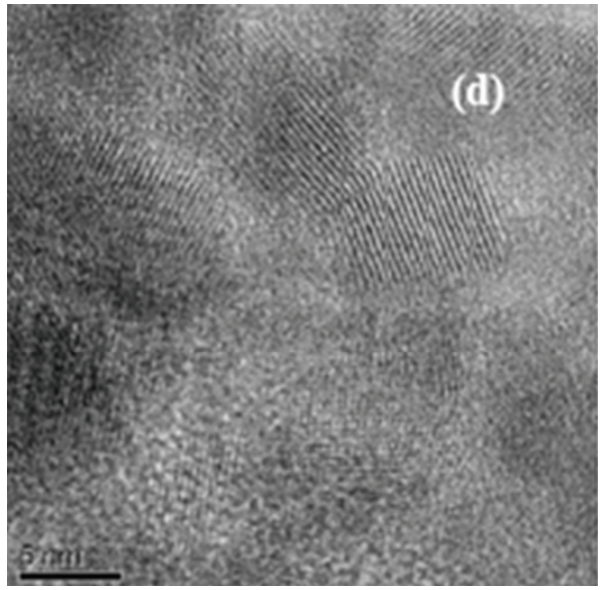

(d)

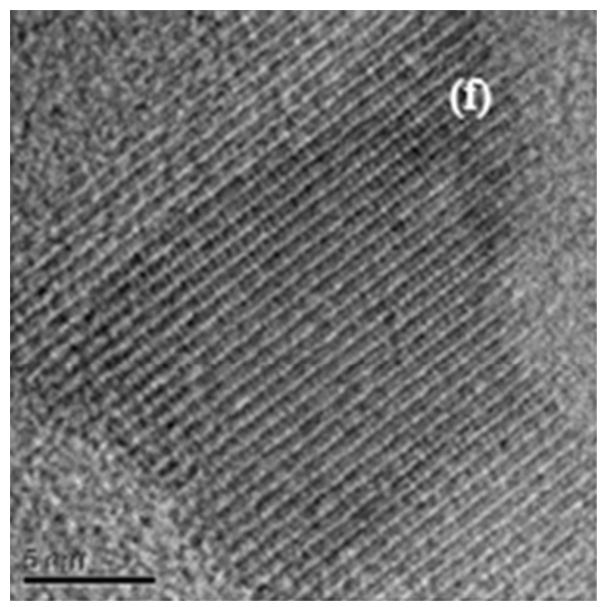

(f)

Figure 5: TEM ((a), (c), (e)) and HR-TEM ((b), (d), (f)) images of the continuous $\mathrm{TiO}_{2}$ fibers calcined $300^{\circ} \mathrm{C}(\mathrm{a})(\mathrm{b}) ; 500^{\circ} \mathrm{C}(\mathrm{c})(\mathrm{d}) ; 700^{\circ} \mathrm{C}$ (e) (f) using steam activation for $90 \mathrm{~min}$.

The crystalline size involved two types: the smaller size (about $30 \mathrm{~nm}$ ) and the bigger size (about $50 \mathrm{~nm}$ ). The lattice fringes appeared clear, indicating that the crystalline was well. For the samples of $700^{\circ} \mathrm{C}$ calcination using steam activation, the crystalline size was about $100 \mathrm{~nm}$ and the lattice fringes were very clear. The results indicated that the crystalline size appeared bigger, and the crystalline degree was better with increasing of calcination temperature, which was in good agreement with the results from XRD analysis.

To demonstrate the effect of calcination temperature using steam activation on the particle of surface and the structure inside the continuous $\mathrm{TiO}_{2}$ fibers, SEM images 


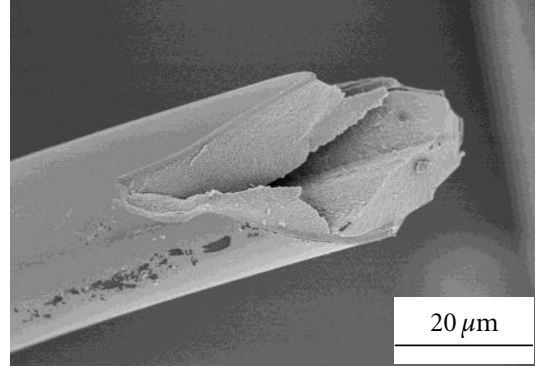

(a)

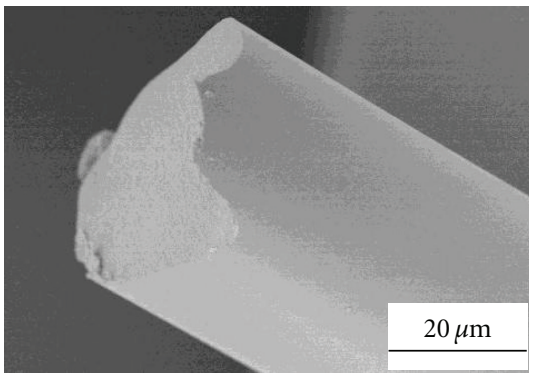

(d)

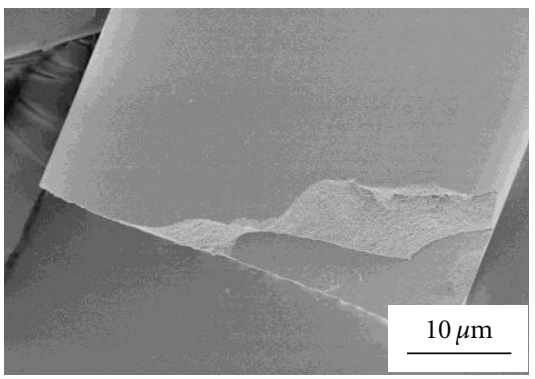

(g)

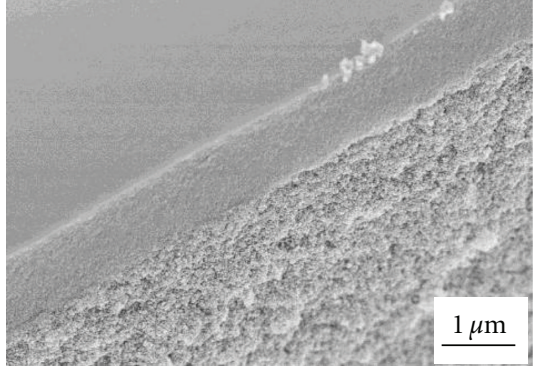

(b)

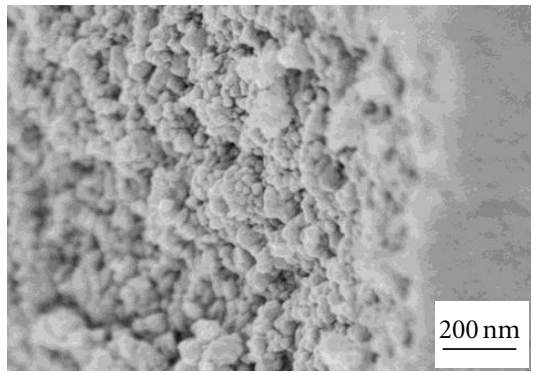

(e)

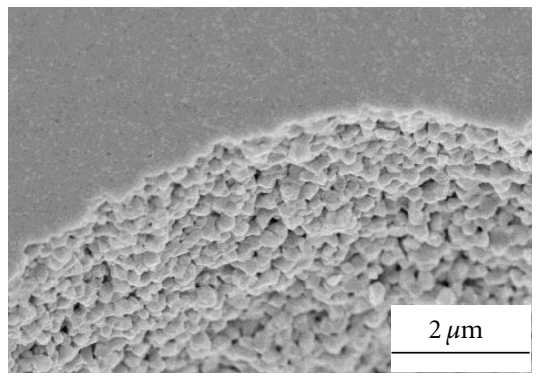

(h)

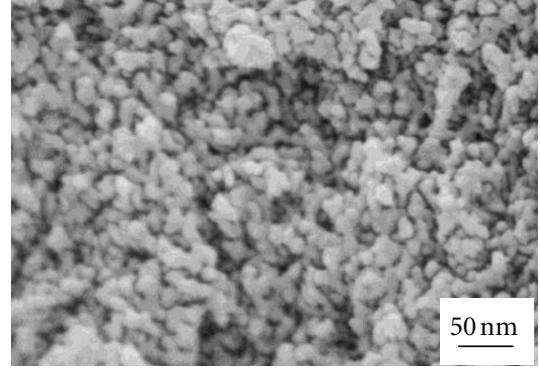

(c)

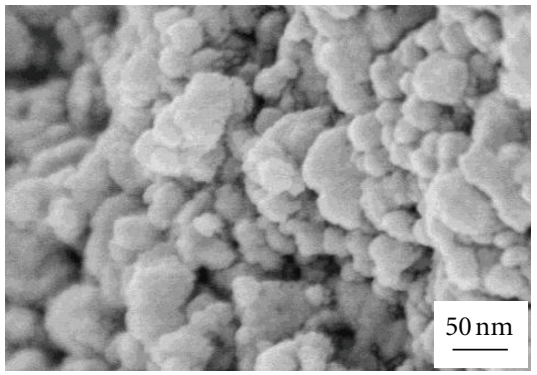

(f)

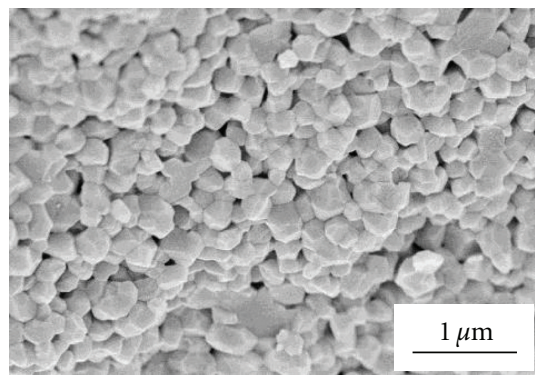

(i)

Figure 6: SEM images of the continuous $\mathrm{TiO}_{2}$ fibers calcined $300^{\circ} \mathrm{C}((\mathrm{a}),(\mathrm{b})$, and $(\mathrm{c})) ; 500^{\circ} \mathrm{C}((\mathrm{d}),(\mathrm{e})$, and $(\mathrm{f}))$ and $700^{\circ} \mathrm{C}((\mathrm{g}),(\mathrm{h})$, and (i)) using steam activation for $90 \mathrm{~min}$.

of the continuous $\mathrm{TiO}_{2}$ fibers calcined $300^{\circ} \mathrm{C}, 500^{\circ} \mathrm{C}$, and $700^{\circ} \mathrm{C}$ using steam activation for $90 \mathrm{~min}$ were shown in Figure 6. From the SEM image, it can be seen that the asprepared fibers have smooth surfaces and are composed of spherical shape nanoparticles, and the crystalline size gradually increased with increasing the calcination temperature. The average diameters of the fibers are in the range of 20 $30 \mu \mathrm{m}$, and the length could reach tens of centimeters, even in continuous fibers $(>1 \mathrm{~m})$. In the middle layer, particles arrayed loosely because of the heat treatment were infiltrated gradually from surface to inside. Grain clusters were formed in the inside layer. As may clearly be seen, some small pores are observed, which is beneficial for being used as catalyst supports because of large surface areas. Because TTBO can be rapidly hydrolyzed by moisture in air, continuous networks (gels) of $\mathrm{TiO}_{2}$ sols formed in the nanofibers after they had been forced out of the tip of the needle during spinning of the $\mathrm{TiO}_{2}$ precursor [20]. Solidification occurs more rapidly in the sheath than in the core [21]. As a result, microphase separation between $\mathrm{TiO}_{2}$ and the PVP solution occurred during solidification. However, it could be seen that the crystalline size of the $500^{\circ} \mathrm{C}$ calcination using steam activation was rather complicated. As mentioned above, the fibers annealed at $500^{\circ} \mathrm{C}$ using steam activation exhibited rutile and anatase phases, which were the results from XRD and TEM analysis.

The grain growth depends on sintering temperatures and time, which can be analyzed by well-known grain growth kinetics equation $[22,23]$ :

$$
D^{n}-D_{0}^{n}=k_{0} t \exp \left(\frac{-E}{R T}\right)=k t
$$

where $D$ is the final average grain size, $D_{0}$ is the initial average grain size, $n$ is the growth exponent, $k$ is a rate constant, $k_{0}$ is a preexponential constant, $E$ is the activation energy of grain growth, $R$ is the gas constant, and $T$ is absolute temperature. When $D_{0}$ is significantly smaller than $D, D_{0}^{n}$ can be neglected relative to $D^{n}$. Equation (3) can be simplified as follows:

$$
D^{n}=k_{0} t \exp \left(\frac{-E}{R T}\right)=k t .
$$




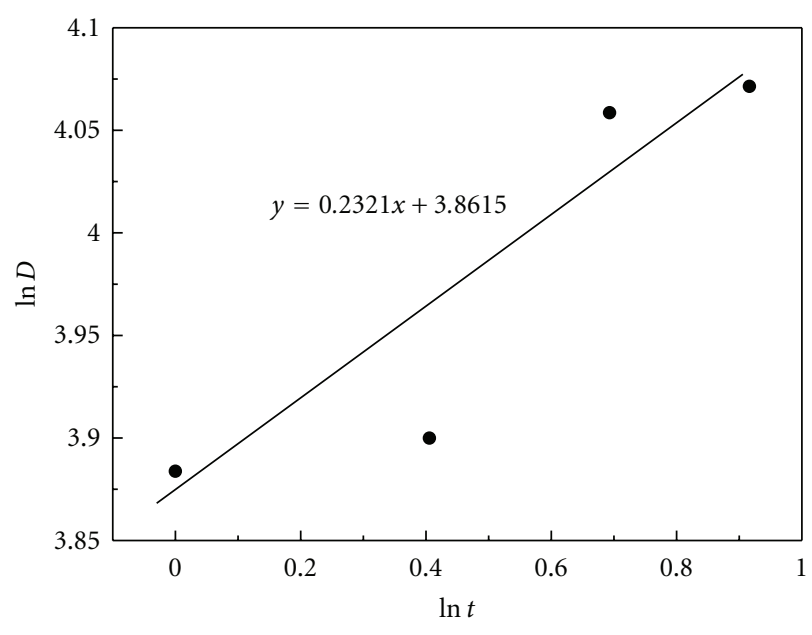

Figure 7: Relationship between $\ln D$ and $\ln t$ of the rutile crystalline phase in the continuous $\mathrm{TiO}_{2}$ fibers.

By taking logarithms, (4) can be rewritten as

$$
\ln D=\frac{1}{n} \ln k+\frac{1}{n} \ln t
$$

Based on (3) and results of Figure 4, the relationship between $\ln D$ and $\ln t$ of the rutile crystalline phase in the continuous $\mathrm{TiO}_{2}$ fibers was shown in Figure 7. The $n$ value and $k$ value of rutile crystalline phase in the continuous $\mathrm{TiO}_{2}$ fibers at $500^{\circ} \mathrm{C}$ were 4 and $2.55 \times 10^{6} \mathrm{~nm} / \mathrm{h}$, respectively. The growth exponent of the rutile crystal phase inside the $\mathrm{TiO}_{2}$ fiber was 4 , and (4) can be rewritten as

$$
D^{4}=k_{0} \exp \left(\frac{-E}{R T}\right) .
$$

Equation (4) can be rewritten as by taking logarithms:

$$
4 \ln D=\ln k_{0}-\frac{E}{R T} .
$$

Straight lines of $\ln D$ against $1 / T$ (Figure 8) are plotted according to (7). The activation energies at $500^{\circ} \mathrm{C} \sim 700^{\circ} \mathrm{C}$ and $700^{\circ} \mathrm{C} \sim 800^{\circ} \mathrm{C}$ were $38.62 \mathrm{~kJ} / \mathrm{mol}$ and $143.91 \mathrm{~kJ} / \mathrm{mol}$, respectively. The results explained that the crystal size of rutile $\mathrm{TiO}_{2}$ increased slowly at $500^{\circ} \mathrm{C} \sim 700^{\circ} \mathrm{C}$ and rapidly increased at $700^{\circ} \mathrm{C} \sim 800^{\circ} \mathrm{C}$, respectively. The kinetics of crystalline growth of rutile phase would become slow due to the diffuse of particle decreasing at relatively low thermal treatment temperature. The steam activation thermal treatment has more remarkable effects on the growth of nanocrystallites in the continuous $\mathrm{TiO}_{2}$ fibers.

\section{Conclusions}

The continuous $\mathrm{TiO}_{2}$ fibers have been synthesized by the solgel method using steam activation thermal treatment. The results demonstrate that the average diameters of the fibers are in the range of $20-30 \mu \mathrm{m}$ and are cylindrical composed of nanoparticles. The crystal size became bigger with

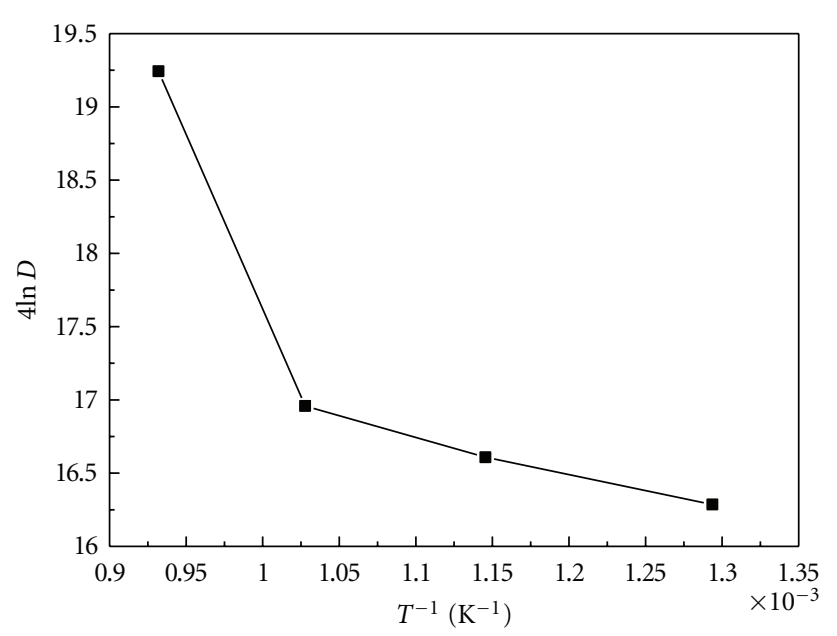

Figure 8: Relationship between $\ln D$ and $1 / T$ of the rutile crystalline phase in the continuous $\mathrm{TiO}_{2}$ fibers.

increasing the thermal treatment temperture using steam activation. The crystal phase of the synthesized $\mathrm{TiO}_{2}$ fiber was transformed from anasate to rutile crystalline phase increasing the steam activated time, and the amount of the anatase crystalline phase decreased from $73.3 \%$ to $11.9 \%$, the crystal size of anatase crystalline phase increased from $18.5 \mathrm{~nm}$ to $37.4 \mathrm{~nm}$, and the crystal size of rutile crystalline phase increased from $44.6 \mathrm{~nm}$ to $58.6 \mathrm{~nm}$. The growth exponent and the constant of growth rate of the rutile crystal phase inside the $\mathrm{TiO}_{2}$ fibers were 4 and $2.55 \times 10^{6} \mathrm{~nm} / \mathrm{h}$, respectively. The activation energies of crystalline growth were $38.62 \mathrm{~kJ} / \mathrm{mol}$ and $143.91 \mathrm{~kJ} / \mathrm{mol}$ in the thermal treated temperture range of $500^{\circ} \mathrm{C} \sim 700^{\circ} \mathrm{C}$ and $700^{\circ} \mathrm{C} \sim 800^{\circ} \mathrm{C}$, respectively. The results show that steam activation thermal treatments have more remarkable effects on the growth of nanocrystallites in the continuous $\mathrm{TiO}_{2}$ fibers.

\section{Acknowledgments}

This work was supported by the Program for the National Natural Science Foundation of China (50872014, 51102026) and Aid program for Science and Technology Innovative Research Team in Higher Educational Institutions of Hunan Province.

\section{References}

[1] A. Fujishima and K. Honda, "Electrochemical photolysis of water at a semiconductor electrode," Nature, vol. 238, no. 5358, pp. 37-38, 1972.

[2] H. Tong, S. Ouyang, Y. Bi, N. Umezawa, M. Oshikiri, and J. Ye, "Nano-photocatalytic materials: possibilities and challenges," Advanced Materials, vol. 24, no. 2, pp. 229-251, 2012.

[3] A. M. Smith and S. Nie, "Semiconductor nanocrystals: structure, properties, and band gap engineering," Accounts of Chemical Research, vol. 43, no. 2, pp. 190-200, 2010.

[4] D. Y. C. Leung, X. Fu, C. Wang et al., "Hydrogen production over titania-based photocatalysts," ChemSusChem, vol. 3, no. 6, pp. 681-694, 2010. 
[5] Q. Xiang, J. Yu, and M. Jaroniec, "Synergetic effect of $\mathrm{MoS}_{2}$ and graphene as cocatalysts for enhanced photocatalytic $\mathrm{H}_{2}$ production activity of $\mathrm{TiO}_{2}$ nanoparticles," Journal of the American Chemical Society, vol. 134, no. 15, pp. 6575-6578, 2012.

[6] T. Guo, L. Wang, D. G. Evans, and W. Yang, "Synthesis and photocatalytic properties of a polyaniline-intercalated layered protonic titanate nanocomposite with a $\mathrm{p}-\mathrm{n}$ heterojunction structure," The Journal of Physical Chemistry C, vol. 114, no. 11, pp. 4765-4772, 2010.

[7] S. A. Elfeky and A.-S. A. Al-Sherbini, "Photo-oxidation of rhodamine-6-G via $\mathrm{TiO}_{2}$ and $\mathrm{Au} / \mathrm{TiO}_{2}$-bound polythene beads," Journal of Nanomaterials, vol. 2011, Article ID 570438, 8 pages, 2011.

[8] Y. Yu and D. Xu, "Single-crystalline $\mathrm{TiO}_{2}$ nanorods: highly active and easily recycled photocatalysts," Applied Catalysis B, vol. 73, no. 1-2, pp. 166-171, 2007.

[9] S. Liu, C. Liu, W. Wang, B. Cheng, and J. Yu, "Unique photocatalytic oxidation reactivity and selectivity of $\mathrm{TiO}_{2}$-graphene nanocomposites," Nanoscale, vol. 4, no. 10, pp. 3193-3200, 2012.

[10] Y. Qiu and J. Yu, "Synthesis of titanium dioxide nanotubes from electrospun fiber templates," Solid State Communications, vol. 148, no. 11-12, pp. 556-558, 2008.

[11] X. Zhou, J. Lu, L. Li, and Z. Wang, "Preparation of crystalline Sn-Doped $\mathrm{TiO}_{2}$ and its application in visible-light photocatalysis," Journal of Nanomaterials, vol. 2011, Article ID 432947, 5 pages, 2011.

[12] A. Formhals, "Process and apparatus for preparing artificial threads," Patent, no.1975504, 1934.

[13] L. Y. Zhu, G. Yu, X. Q. Wang, and D. Xu, "Preparation and characterization of $\mathrm{TiO}_{2}$ fiber with a facile polyorganotitanium precursor method," Journal of Colloid and Interface Science, vol. 336, no. 2, pp. 438-442, 2009.

[14] R. Yuan, X. Fu, X. Wang et al., "Template synthesis of hollow metal oxide fibers with hierarchical architecture," Chemistry of Materials, vol. 18, no. 19, pp. 4700-4705, 2006.

[15] Z. Cai, J. Li, and Y. Wang, "Fabrication of zinc titanate nanofibers by electrospinning technique," Journal of Alloys and Compounds, vol. 489, no. 1, pp. 167-169, 2010.

[16] H. M. Yang, X. C. Zhang, and Q. F. Tao, "Synthesis and characterization of sol-gel derived $\mathrm{TiO}_{2}$ thin films: effect of different pretreatment process," Inorganic Materials, vol. 45, no. 10, pp. 1139-1145, 2009.

[17] F. Gao, D. L. Zhao, Y. Li, and X. G. Li, "Preparation and hydrogen storage of activated rayon-based carbon fibers with high specific surface area," Journal of Physics and Chemistry of Solids, vol. 71, no. 4, pp. 444-447, 2010.

[18] F. Salvador, M. J. Sánchez-Montero, J. Montero, and C. Izquierdo, "Activated carbon fibers prepared from a phenolic fiber by supercritical water and steam activation," The Journal of Physical Chemistry C, vol. 112, no. 50, pp. 20057-20064, 2008.

[19] S. Qiu and S. J. Kalita, "Synthesis, processing and characterization of nanocrystalline titanium dioxide," Materials Science and Engineering A, vol. 435-436, pp. 327-332, 2006.

[20] N. Bao, Z. Wei, Z. Ma, F. Liu, and G. Yin, "Si-doped mesoporous $\mathrm{TiO}_{2}$ continuous fibers: preparation by centrifugal spinning and photocatalytic properties," Journal of Hazardous Materials, vol. 174, no. 1-3, pp. 129-136, 2010.

[21] H. Widiyandari, M. M. Munir, F. Iskandar, and K. Okuyama, "Morphology-controlled synthesis of chromia-titania nanofibers via electrospinning followed by annealing," Materials Chemistry and Physics, vol. 116, no. 1, pp. 169-174, 2009.
[22] T. Ozawa, "Kinetic analysis by repeated temperature scanning. Part 1. Theory and methods," Thermochimica Acta, vol. 356, no. 1-2, pp. 173-180, 2000.

[23] T. Zhang, P. Hing, H. Huang, and J. Kilner, "Sintering study on commercial $\mathrm{CeO}_{2}$ powder with small amount of $\mathrm{MnO}_{2}$ doping," Materials Letters, vol. 57, no. 2, pp. 507-512, 2002. 

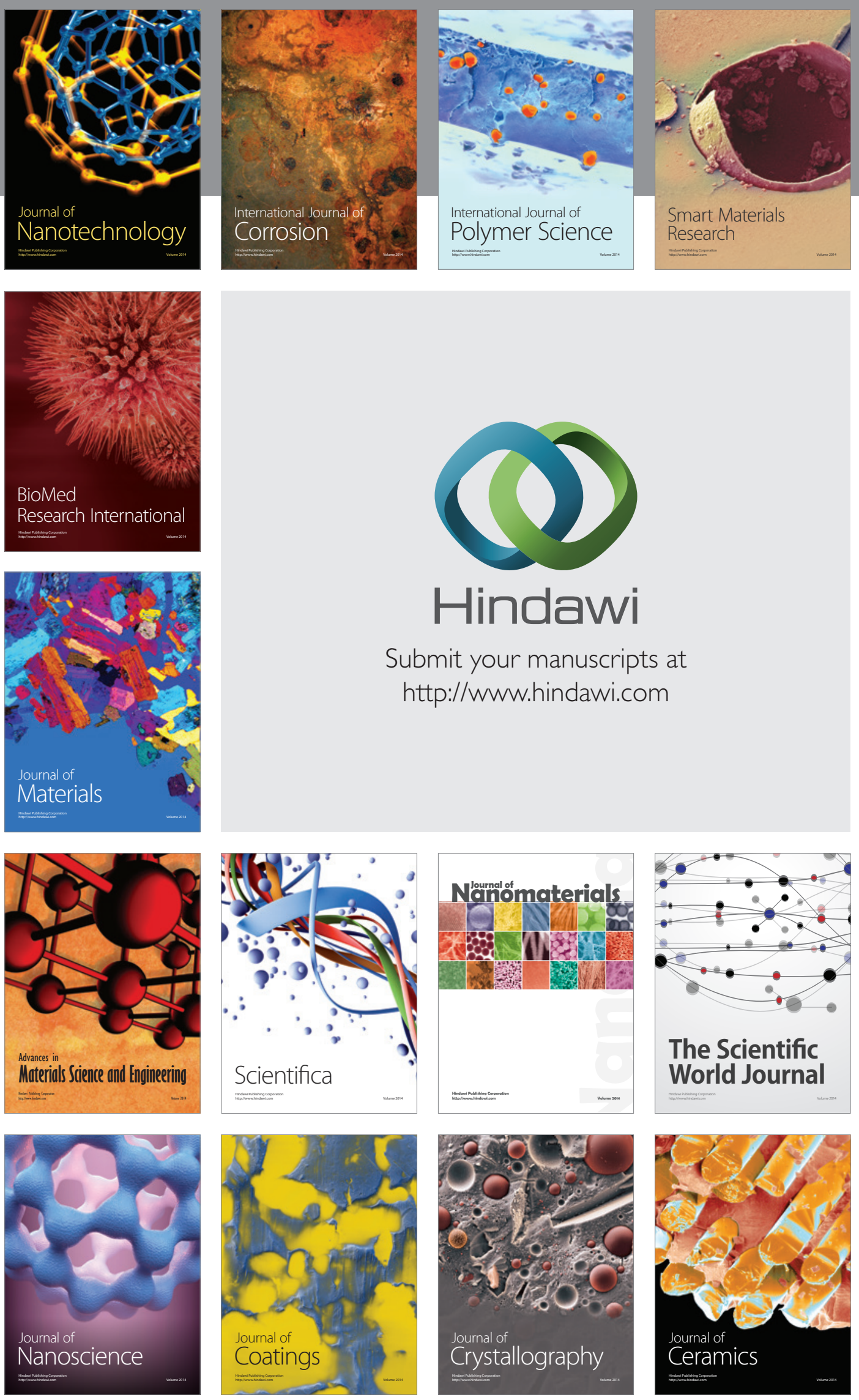

The Scientific World Journal

Submit your manuscripts at

http://www.hindawi.com

\section{World Journal}

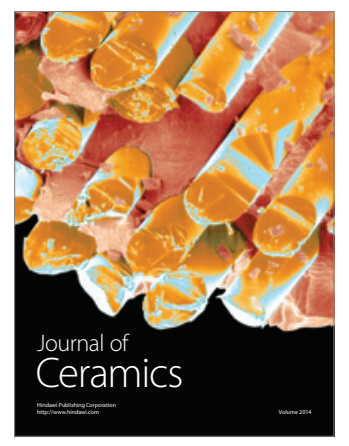

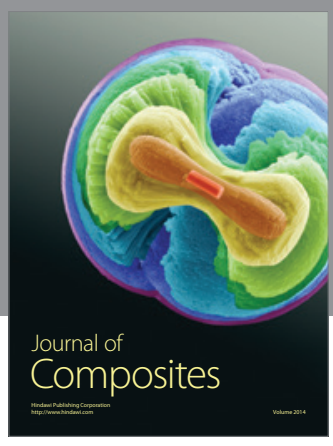
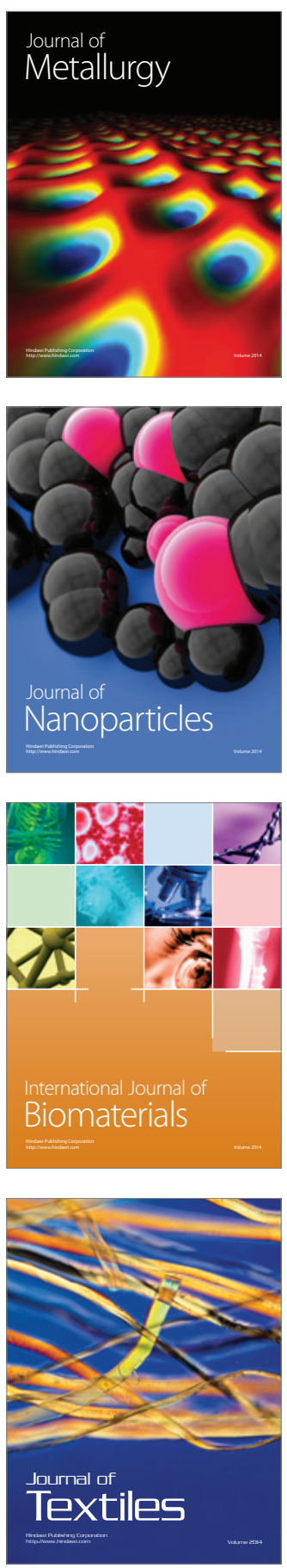